\title{
An idealized model of tidal dynamics in the North Sea: resonance properties and response to large-scale changes
}

\author{
Pieter C. Roos • Jorick J. Velema • \\ Suzanne J. M. H. Hulscher • Ad Stolk
}

Received: 29 March 2011 / Accepted: 13 June 2011 / Published online: 19 July 2011

(C) The Author(s) 2011. This article is published with open access at Springerlink.com

\begin{abstract}
An idealized process-based model is developed to investigate tidal dynamics in the North Sea. The model geometry consists of a sequence of different rectangular compartments of uniform depth, thus, accounting for width and depth variations in a stepwise manner. This schematization allows for a quick and transparent solution procedure. The solution, forced by incoming Kelvin waves at the open boundaries and satisfying the linear shallow water equations on the $f$ plane with bottom friction, is in each compartment written as a superposition of eigenmodes, i.e. Kelvin and Poincaré waves. A collocation method is employed to satisfy boundary and matching conditions. First, the general resonance properties of a strongly simplified geometry with two compartments, representing the Northern North Sea and Southern Bight, are studied. Varying the forcing frequency while neglecting bottom friction reveals Kelvin and Poincaré resonance. These resonances continue to exist (but with lower amplification and a modified spatial structure) when adding the Dover Strait as a third compartment and separating the solutions due to forcing from either
\end{abstract}

Responsible Editor: Joachim W. Dippner

P. C. Roos $(\varangle)$ · J. J. Velema · S. J. M. H. Hulscher Department of Water Engineering and Management, Faculty of Engineering Technology, University of Twente, P.O. Box 217, 7500 AE Enschede, The Netherlands e-mail: p.c.roos@utwente.nl

A. Stolk

Rijkswaterstaat Noordzee, Ministry of Infrastructure and the Environment, P.O. Box 5807, 2280 HV Rijswijk,

The Netherlands the north or the south only. Including bottom friction dampens the peaks. Next, comparison with tide observations along the North Sea coast shows remarkable agreement for both semi-diurnal and diurnal tides. This result is achieved with a more detailed geometry consisting of 12 compartments fitted to the coastline of the North Sea. Further simulations emphasize the importance of Dover Strait and bottom friction. Finally, it is found that a sea level rise of $1 \mathrm{~m}$, uniformly applied to the entire North Sea, amplifies the M2-elevation amplitudes almost everywhere along the coast, with an increase of up to $8 \mathrm{~cm}$ in Dover Strait. Bed level changes of $\pm 1 \mathrm{~m}$, uniformly applied to the Southern Bight only, imply weaker changes, with changes in coastal M2-elevation amplitudes below $5 \mathrm{~cm}$.

Keywords Tides $\cdot$ North Sea $\cdot$ Resonance . Sea level rise

\section{Introduction}

Understanding tidal dynamics in the North Sea is important for navigation, coastal safety and ecology. This link is both direct, through fluctuating water levels and oscillatory currents, and indirect, through the dynamics of tide-induced bed forms (Dyer and Huntley 1999). Of particular interest is the tide's response to largescale changes due to human intervention (de Boer et al. 2011) and sea level rise.

Tide observations in the North Sea indicate a predominant semi-diurnal character (Otto et al. 1990; Huthnance 1991). Semi-diurnal lunar (M2) elevation amplitudes are of the order of $1 \mathrm{~m}$. Diurnal components are weaker, with coastal elevation amplitudes of K1 
Fig. 1 Bathymetric chart of the North Sea, with depth below MSL in $\mathrm{m}$ (data source: Amante and Eakins 2009). White lines indicate the idealized model geometry consisting of 12 rectangular compartments to be used in this study (points $A$ to $F$ introduced are for convenience). Open circles denote the coastal tide stations involved in the comparison between model results and observations. Small dots indicate other tide stations not considered in this study (British Admiralty 2009a, b)
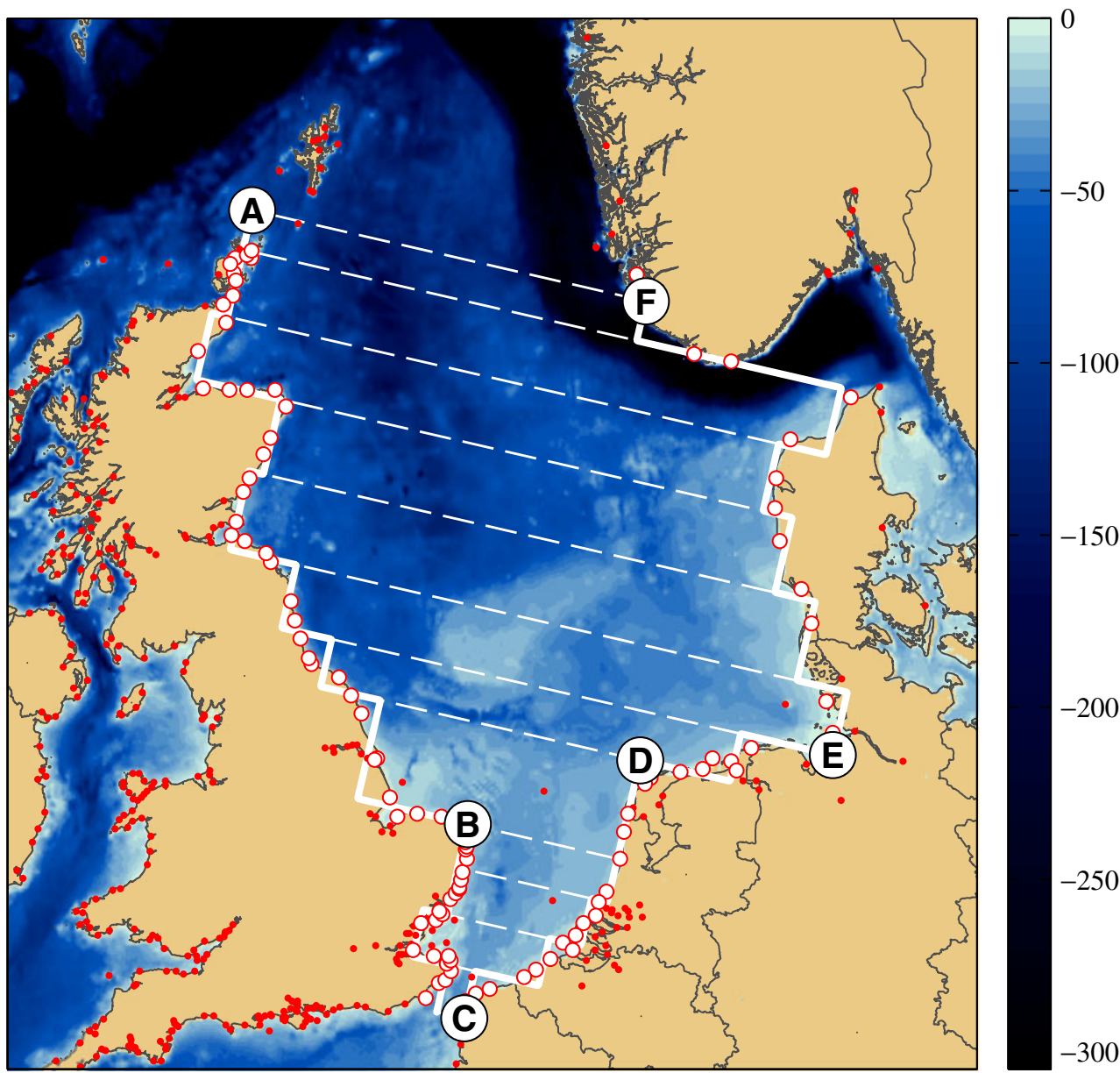

and $\mathrm{O} 1$ of about $10 \mathrm{~cm}$. Figure 1 shows the locations of coastal tide stations where harmonic constants, i.e. tidal range and phase of the four most important constituents (M2, S2, K1 and O1) are available (Bristish Admiralty2009a, b).

North Sea tides result primarily from co-oscillation with the Atlantic (Defant 1961). Their complexity is due to several factors (see Fig. 1):

- Significant variations in depth, ranging roughly from $20-150 \mathrm{~m}$ from south to north, dissipation through bottom friction being important in the shallower parts. The Norwegian Trench in the northeast has depths of up to $700 \mathrm{~m}$.

- Significant basin width, relative to the Rossby deformation radius, emphasizing the importance of rotation.

- Significant variations in basin width, ranging from over $500 \mathrm{~km}$ in the north to about $200 \mathrm{~km}$ in the Southern Bight (points $B C D$ ) and less than $40 \mathrm{~km}$ in the Dover Strait (point $C$ ). In combination with the preceding point, this explains the profound twodimensional spatial structure of the tide.
- The presence of two open boundaries to the Atlantic: east of Scotland and Dover Strait. ${ }^{1}$

Detailed numerical model studies have been carried out to reproduce the tide observations mentioned above (Sinha and Pingree 1997; Davies and Kwong 2000, see Fig. 2). Such numerical tide simulations are a key factor in the water level forecasts for a storm surge warning system; e.g. in the Dutch Continental Shelf model (Gerritsen et al. 1995; Verlaan et al. 2005). Numerical models are generally computationally expensive and not aimed at obtaining insight in the physics, which limits their suitability for a systematic study of the resonance properties of the North Sea.

On the other hand, idealized process-based models are specifically designed to obtain insight in tidal dynamics. Taylor's (1922) classical solution to the problem of Kelvin wave reflection in a rectangular rotating basin of uniform depth and width explains elevation

\footnotetext{
${ }^{1}$ The tidal energy flux through the Skagerrak in the east is two orders of magnitude smaller (Barthel et al. 2004).
} 

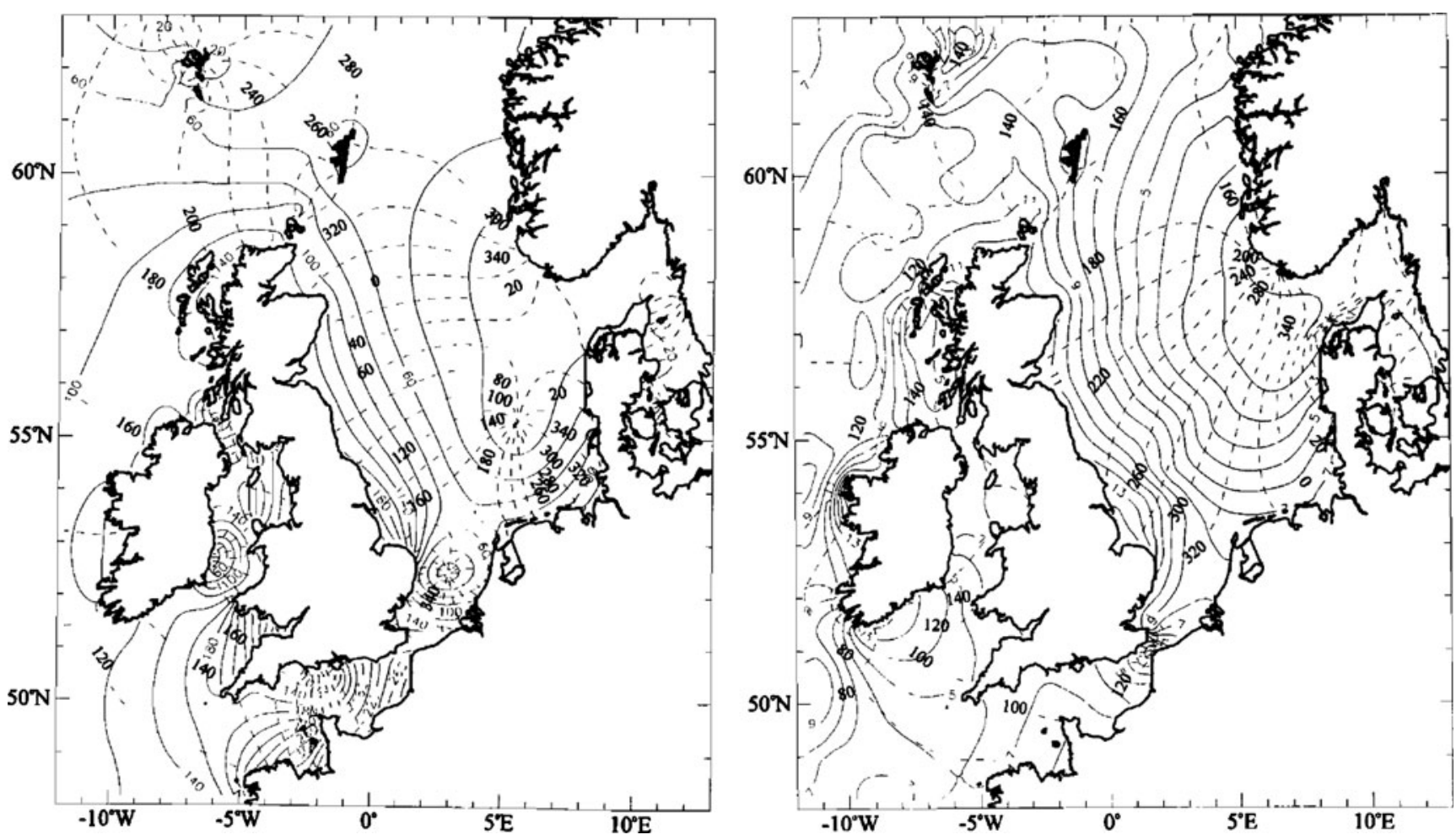

Fig. 2 Co-tidal charts of M2-tide (left) and K1-tide (right), with elevation amplitudes in cm (solid) and phases in degrees (dashed), as obtained with a numerical model (Davies and Kwong 2000, reprinted with permission from the American Geophysical Union)

amphidromic points (no surface fluctuations) and current amphidromic points (no velocities) occurring alternately on the centerline of the basin. Incorporating dissipation causes the amphidromes to shift in the crossbasin direction (Rienecker and Teubner 1980; Rizal 2002; Roos and Schuttelaars 2009). To mimic Dover Strait, Brown $(1987,1989)$ imposed an oscillating free surface elevation at the head, which causes an alongbasin shift of the amphidromes. We note that also complex numerical models have been run with simplified geometries, to study the frictional and wind effects with a three-dimensional model (Davies and Jones 1995, 1996), the influence of basin geometry on the current amphidromic system (Xia et al. 1995) and sandbank formation (Carbajal et al. 2005). Table 1 summarizes the tidal basins around the world that have been studied using (extensions of) Taylor's (1922) idealized model. Although the idealized studies mentioned above provide qualitative insight, the rather strong geometrical schematizations preclude a more specific understanding of the North Sea tides.

A third class of studies specifically focused on the resonance properties of tidal basins, which is indicative of their response to large-scale changes. A classical result for semi-enclosed bays co-oscillating with a larger sea/ocean states that resonance occurs when basin length equals one quarter of the shallow water wavelength (or an odd multiple; see e.g. Defant 1961). This theory, however, ignores radiative damping into the adjacent sea/ocean (Garrett 1975) and is only valid for narrow rectangular bays of uniform depth and width. Rotation complicates the resonance properties of wider basins, which also allow for a cross-bay halfwave ${ }^{2}$ resonance (Huthnance 1980). ${ }^{3}$ This type of resonance, associated with amplification of Poincaré modes, is also possible in wide embayments of uniform width with a shallow zone near the head (Webb 1976; Roos and Schuttelaars 2011). Alternatively, the resonant frequencies of various basins around the world have been estimated by fitting analytical frequency-response curves to tide observations (Garrett 1972; Godin 1993; Sutherland et al. 2005; Arbic et al. 2007). The curves are derived from e.g. the rectangular bay model mentioned above (or a Helmholtz oscillator for smaller basins),

\footnotetext{
${ }^{2}$ Or an integer multiple of this one half wave: one wave, three halve waves, etc.

${ }^{3}$ Huthnance (1980) used the term 'resonance' only to denote infinite amplification and uses 'maximum response' in the case of a peak that is finite due to friction, radiation damping and rotation. In the present study, we use the term 'resonance' to denote any peak response.
} 
Table 1 Overview of studies extending Taylor's (1922) approach and applying it to basins other than the North Sea

\begin{tabular}{|c|c|c|c|c|c|}
\hline Reference & Application & Constituent(s) & \# Comp. & $\begin{array}{l}\text { Width } \\
\text { variations }\end{array}$ & $\begin{array}{l}\text { Bottom } \\
\text { friction }\end{array}$ \\
\hline Godin (1965) & Labrador Sea/Davis Str./Baffin Bay & M2 & 3 & Yes & No \\
\hline Hendershott and Speranza (1971) & Adriatic Sea, Gulf of California & M2 & $1^{\mathrm{a}}$ & No & $\mathrm{No}^{\mathrm{a}, \mathrm{b}}$ \\
\hline Webb (1976) & Patagonian Shelf & $\mathrm{M} 2^{\mathrm{c}}$ & 2 & No & Yes \\
\hline Kowalik (1979) & Arctic Sea & M2 & $2^{\mathrm{d}}$ & $\mathrm{n} / \mathrm{a}^{\mathrm{d}}$ & Yes \\
\hline Huthnance (1980) & Brazilian shelf & M3 & $2^{\mathrm{e}}$ & $\mathrm{Yes}^{\mathrm{e}}$ & Yes \\
\hline Kang (1984) & Yellow Sea & $\mathrm{M} 2, \mathrm{~K} 1$ & $1^{\mathrm{f}}$ & No & No \\
\hline Mosetti (1986) & Northern Adriatic & M2 & 1 & No & No \\
\hline Yanagi (1987) & Bungo and Kii Channel (Japan) & M2 & $1^{\mathrm{a}}$ & No & No \\
\hline Fang et al. (1991) & Yellow Sea & M2 & $1^{\mathrm{f}, \mathrm{g}}$ & No & Yes \\
\hline Rizal (2000) & Malacca Strait & M2 & 1 & No & Yes \\
\hline Jung et al. (2005) & Yellow Sea, East China Sea & M2 & $3^{\mathrm{g}}$ & No & Yes \\
\hline Roos and Schuttelaars (2011) & Adr. Sea, Gulf of Cal., Persian Gulf & $\mathrm{M} 2, \mathrm{~S} 2, \mathrm{~K} 1, \mathrm{O} 1$ & $2,3^{\mathrm{h}}$ & No & Yes \\
\hline
\end{tabular}

a Superposition of two Kelvin waves without bottom friction

${ }^{b}$ Partial absorption at bay head, a region not explicitly resolved, explains the amplitude reduction and phase lag of the reflected Kelvin wave

${ }^{\mathrm{c}}$ The system's resonant period is estimated at $10.8 \mathrm{~h}(2.23 \mathrm{cpd})$, near the semi-diurnal band; forcing frequency further treated as a complex quantity

${ }^{\mathrm{d}}$ Frictionless Kelvin wave in channel, Sverdrup wave in circular basin's interior; no systematic matching of these two solutions

e Extending Garrett's (1975) analysis to wide gulfs, explaining ocean-shelf resonance

${ }^{f}$ Part of bay head as open boundary

gSpecifying elevation amplitude at bay mouth (rather than sending in a Kelvin wave)

${ }^{\mathrm{h}}$ Also allowing for transverse topographic steps

whereas the observations comprise amplitude gains and phase shifts over the basin for various tidal constituents. This method relies on the availability of observations at different tidal frequencies, their proximity to resonance and the validity of the model underlying the adopted frequency-response curve.

The present study is aimed at understanding tidal dynamics in the North Sea, particularly its resonance properties and its response to large-scale changes. Motivated by the lack of geometrical detail in existing idealized model studies and the limited suitability of numerical models for this purpose, we present a new idealized model (Fig. 1). Innovative aspects of our work are the model geometry (many compartments, depth and width variations, two open boundaries), the focus on resonance properties, and the detailed comparison with semi-diurnal and diurnal tide observations along the North Sea coast. Our approach largely follows that of Roos and Schuttelaars (2011) but involves the necessary extensions to make it suitable for the North Sea.

This paper is organized as follows. The model setup and solution method are presented in Section 2. In Section 3 , we investigate the general resonance properties of a relatively shallow compartment connected to a wider and deeper compartment and to a narrow strait. A crucial next step is then to show that our model is quantitatively capable of reproducing tidal dynamics as observed in the North Sea (tide stations in Fig. 1). As shown in Section 4, good agreement with semi- diurnal and diurnal tide observations is achieved with a geometry consisting of 12 compartments. This result gives confidence in the model's reliability in situations for which no observational data are available. Further simulations, presented in Section 5, then provide insight into:

- The importance of the tidal energy fluxes from the north (east of Scotland) and the south (through Dover Strait) as well as the effects of closure of Dover Strait

- The role of bottom friction

- The effects of sea level rise, simulated by an overall increase in water depth

- The system's sensitivity to bed level variations in the Southern Bight

Finally, Sections 6 and 7 contain the discussion and conclusions, respectively.

\section{Model}

\subsection{Model formulation}

Consider a tidal wave of angular frequency $\omega$ and typical elevation amplitude $Z$. The model geometry consists of a sequence of $J$ rectangular compartments of length $l_{j}$, width $b_{j}$ and (uniform) depth $h_{j}$ (Fig. 3). The geometries in Fig. 3a, b will be used in Section 3 
(a) Two compartments

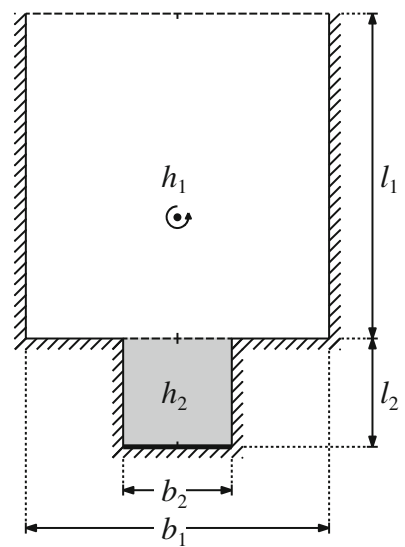

(b) Three compartments (including strait)

(c) North Sea fit
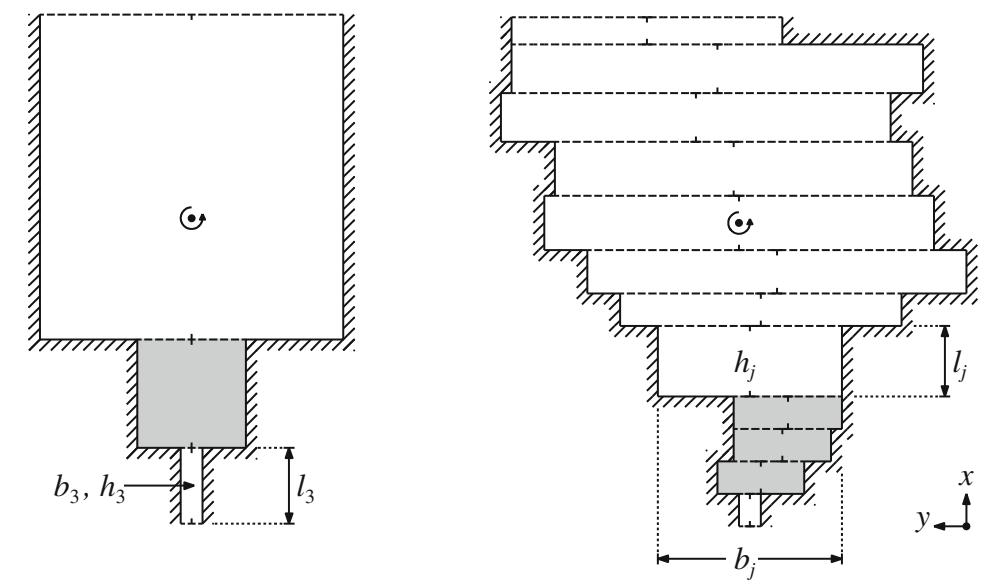

Fig. 3 Definition sketch of the model geometry, showing a a simple set-up with two compartments, $\mathbf{b}$ extension with strait and $\mathbf{c}$ the North Sea fit with 12 compartments also shown in Figs. 1 and 6. Shaded compartments represent the Southern Bight; details in Table 3

to investigate general resonance properties. The more detailed geometry in Fig. 3c will be used in Section 4 to reproduce tide observations in the North Sea and forms the basis of further simulations in Section 5. Details of these configurations are given in Table 3 , where $\delta_{j}$ denotes the displacement of compartment $j$ 's centerline with respect to that of compartment $j-1$.

The compartment widths are not small compared with the (local) Rossby deformation radius, which shows the importance of adopting a horizontally twodimensional approach including rotation. Assuming that $Z / h_{j} \ll 1$, conservation of momentum and mass is expressed by the depth-averaged linear shallow water equations on the $f$ plane: 4

$$
\begin{gathered}
\frac{\partial u_{j}}{\partial t}-f_{j} v_{j}+\frac{r_{j} u_{j}}{h_{j}}=-g \frac{\partial \eta_{j}}{\partial x}, \\
\frac{\partial v_{j}}{\partial t}+f_{j} u_{j}+\frac{r_{j} v_{j}}{h_{j}}=-g \frac{\partial \eta_{j}}{\partial y}, \\
\frac{\partial \eta_{j}}{\partial t}+h_{j}\left[\frac{\partial u_{j}}{\partial x}+\frac{\partial v_{j}}{\partial y}\right]=0 .
\end{gathered}
$$

For compartment $j, u_{j}$ and $v_{j}$ are the depth-averaged flow velocity components in along-basin $x$ and crossbasin $y$-direction, respectively, and $\eta_{j}$ is the free surface elevation $(j=1, \cdots, J)$. Furthermore, $f_{j}=2 \Omega \sin \vartheta_{j}$ is a Coriolis parameter (with $\Omega=7.292 \times 10^{-5} \mathrm{rad} \mathrm{s}^{-1}$ the angular frequency of the Earth's rotation and $\vartheta_{j}$ the central latitude of compartment $j$ ) and $g=9.81 \mathrm{~m} \mathrm{~s}^{-2}$

\footnotetext{
${ }^{4}$ For a derivation of Eqs.1-3, see e.g. the scaling procedure in
} Roos and Schuttelaars (2009). the gravitational acceleration. Finally, we have introduced a bottom friction coefficient

$r_{j}=\frac{8 c_{\mathrm{D}}\left\langle U_{j}\right\rangle}{3 \pi}, \quad\left\langle U_{j}\right\rangle=\alpha F U_{j}$,

based on linearization of a quadratic friction law while accounting for the simultaneous presence of several tidal components. In Eq. $4, c_{\mathrm{D}}=2.5 \times 10^{-3}$ is a standard drag coefficient. Furthermore, the velocity scale $\left\langle U_{j}\right\rangle$ is a correction of the coastal current amplitude $U_{j}$ of a classical Kelvin wave without bottom friction (Gill 1982):

$U_{j}=Z_{\mathrm{M} 2} \sqrt{\frac{g}{h_{j}}}$.

Here, the coastal elevation amplitude $Z_{\mathrm{M} 2}=1.40 \mathrm{~m}$ is typical for the dominant M2-tide, obtained by averaging over all coastal tide stations under consideration.

Turning back to Eq. 4, the following corrections are made to $U_{j}$ to obtain a proper velocity scale $\left\langle U_{j}\right\rangle$. Firstly, the coefficient $\alpha$ accounts for the fact that current amplitudes throughout the domain are typically smaller than the tidal current amplitudes near the coast $(\alpha<1)$. In Section $4, \alpha$ will be used as a tuning parameter that is assumed identical for all constituents. Secondly, the coefficient $F$ accounts for the fact that the simultaneous presence of several tidal components enhances friction $(F>1)$, particularly for the weaker components (Jeffreys 1970; Pingree 1983; Inoue and Garrett 2007). Properly incorporating this mechanism is important when we use our model to reproduce tide observations in Section 4. To calculate the $F$ values for M2, S2, K1 and O1 in the North Sea, we follow the 
procedure by Inoue and Garrett (2007); see Table 2 and Appendix A. As it turns out, the ratios $F / F_{\mathrm{M} 2}$ are close to the theoretical maximum of 1.5 obtained in the $\epsilon \downarrow 0$-limit with $\epsilon=Z / Z_{\mathrm{M} 2}$ (Jeffreys 1970). In Section 3, where we investigate the model's frequency response by varying $\omega$ in a broad range surrounding the tidal bands, we will ignore the presence of other components and take $F=1$.

Our model geometry displays different types of boundaries. At the closed boundaries $\mathscr{B}_{u, j}$ and $\mathscr{B}_{v, j}$ orthogonal to the along-basin and cross-basin direction, respectively, we impose a no-normal flow condition, i.e.

$u_{j}=0, \quad$ for $(x, y) \in \mathscr{B}_{u, j}$,

$v_{j}=0, \quad$ for $(x, y) \in \mathscr{B}_{v, j}$.

Next, continuity of elevation and normal flux is required across the topographic steps $\mathscr{I}_{j, j+1}$ between the adjacent compartments:

$h_{j} u_{j}=h_{j+1} u_{j+1}, \quad \eta_{j}=\eta_{j+1}, \quad$ for $(x, y) \in \mathscr{I}_{j, j+1}$.

Finally, the system is forced by a single Kelvin wave coming in through the open boundary for the geometry in Fig. 3a, or by two Kelvin waves coming in through the two open boundaries for the geometries in Fig. 3b, c. In either case, other waves are allowed to radiate outward. In the case of two incoming Kelvin waves, the solution will also depend on their relative amplitudes and phase lag, which complicates the interpretation of the model results.

\subsection{Solution method}

Let $\phi \equiv(u, v, \eta)$ symbolically denote the solution. In each compartment we seek time-periodic solutions of the form

$\phi_{j} \equiv\left(u_{j}, v_{j}, \eta_{j}\right)=\Re\left\{\left(\hat{u}_{j}, \hat{v}_{j}, \hat{\eta}_{j}\right) \exp (i \omega t)\right\}$,

Table 2 Amplitudes $Z$ and friction coefficients $F$, as used in Eq. 4, of four tidal components in the North Sea

\begin{tabular}{lllllll}
\hline Comp. & $T(\mathrm{~h})$ & $\omega(\mathrm{cpd})^{\mathrm{a}}$ & $Z(\mathrm{~m})^{\mathrm{b}}$ & $\epsilon(-)^{\mathrm{c}}$ & $F(-)$ & $F / F_{\mathrm{M} 2}(-)$ \\
\hline $\mathrm{M} 2$ & 12.42 & 1.932 & 1.40 & - & 1.078 & 1 \\
$\mathrm{~S} 2$ & 12.00 & 2.000 & 0.43 & 0.307 & 1.522 & 1.41 \\
$\mathrm{~K} 1$ & 23.93 & 1.003 & 0.09 & 0.064 & 1.539 & 1.43 \\
$\mathrm{O} 1$ & 25.82 & 0.930 & 0.11 & 0.079 & 1.538 & 1.43 \\
\hline
\end{tabular}

${ }^{\mathrm{a}}$ Tidal frequency in cycles per day

${ }^{b}$ Elevation amplitude obtained by averaging over coastal tide stations

${ }^{\mathrm{c}}$ Amplitude divided by (dominant) M2-amplitude, i.e. $\epsilon=$ $Z / Z_{\mathrm{M} 2}$ with $\Re$ denoting the real part, $\omega$ the angular frequency and $\left(\hat{u}_{j}, \hat{v}_{j}, \hat{\eta}_{j}\right)$ the complex amplitudes of flow and elevation, which depend on $x$ and $y$. These amplitudes are then written as a truncated superposition of fundamental wave solutions in an open channel, i.e. Kelvin and Poincaré modes, propagating or exponentially decaying in the positive and negative $x$-direction (see Appendix B). Since these individual waves satisfy the lateral boundary condition in Eq. 7, so does their superposition in the solution.

A collocation technique is then employed to also satisfy the other no-normal flow condition in Eq. 6 and the matching conditions in Eq. 8. We, thus, extend earlier studies to account for width variations (Webb 1976; Jung et al. 2005; Roos and Schuttelaars 2011). Collocation points are defined with an equidistant spacing along the interfaces and the adjacent closed longitudinal boundaries. ${ }^{5}$ At each collocation point, we require either zero normal flow (if located on a closed boundary) or matching of elevation and normal flux (if located on an interface). The truncation numbers mentioned previously are chosen such to balance the distribution of collocation points. The coefficients of the individual modes then follow from a linear system, which is solved using standard techniques.

In the remainder of this study we adopt an average spacing between collocation points of about $6 \mathrm{~km}$. In Section 3, where we investigate the resonance properties of the simple geometries in Fig. 3a, b, this leads to a total number of about 170 Kelvin and Poincaré modes. In reproducing the tide observations from the North Sea (Section 4; geometry of Fig. 3c), the same spacing implies a total number of about 1700 Kelvin and Poincaré modes in the complete domain.

\section{Results: general resonance properties}

\subsection{Indicators of amplitude gain in the Southern Bight}

To investigate resonance properties, we consider the frequency-response of our model. To this end, we analyze the solution for different values of the forcing frequency $\omega$ in a range that includes the diurnal and semidiurnal tidal bands. This analysis will be carried out for the simple geometries shown in Fig. 3a, b. The first consists of two compartments, representing the relatively wide and deep northern part of the North Sea and the

\footnotetext{
$\overline{5}$ The open boundaries do not require collocation points, since we specify incoming Kelvin waves
} 
Table 3 Compartment properties of the basin geometries in Fig. 3

\begin{tabular}{llllcll}
\hline Fig. & $j$ & $l_{j}(\mathrm{~km})$ & $b_{j}(\mathrm{~km})$ & $h_{j}(\mathrm{~m})$ & $\delta_{j}(\mathrm{~km})^{\mathrm{a}}$ & $\vartheta_{j}\left({ }^{\circ} \mathrm{N}\right)$ \\
\hline $3 \mathrm{a}$ & 1 & 600 & 550 & 80 & - & 56 \\
& $2^{\mathrm{b}}$ & 200 & 200 & 20 & 0 & 52 \\
$3 \mathrm{~b}$ & 1 & 600 & 550 & 80 & - & 56 \\
& $2^{\mathrm{b}}$ & 200 & 200 & 20 & 0 & 52 \\
& 3 & 40 & 35 & 20 & 0 & 51 \\
$3 \mathrm{c}$ & 1 & 50 & 500 & 151.5 & - & 59.0 \\
& 2 & 85 & 760 & 129.9 & -130 & 58.1 \\
& 3 & 85 & 720 & 73.8 & 40 & 57.4 \\
& 4 & 95 & 650 & 65.0 & -72 & 56.5 \\
& 5 & 100 & 720 & 52.9 & -16 & 55.6 \\
& 6 & 80 & 700 & 41.3 & -74 & 54.7 \\
& 7 & 60 & 520 & 39.6 & 27 & 54.1 \\
& 8 & 125 & 330 & 26.7 & 19 & 53.3 \\
& $9^{\mathrm{b}}$ & 55 & 190 & 26.3 & -70 & 52.4 \\
& $10^{\mathrm{b}}$ & 60 & 170 & 24.9 & 10 & 51.9 \\
& $11^{\mathrm{b}}$ & 60 & 160 & 19.5 & 35 & 51.5 \\
& 12 & 60 & 35 & 27.3 & 18 & 51.0 \\
\hline
\end{tabular}

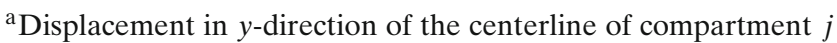
with respect to that of compartment $j-1$

${ }^{\mathrm{b}}$ Compartment(s) representing the Southern Bight (shaded in Fig. 3)

narrower and shallower Southern Bight. This geometry is extended in Fig. $3 b$ by including a third compartment, representing Dover Strait as a second opening to the Atlantic. For simplicity, all compartments have been symmetrically aligned about the basin's central axis, i.e. $\delta_{j}=0$. See Table 3 for the dimensions and latitudes.

(a) Two compartments

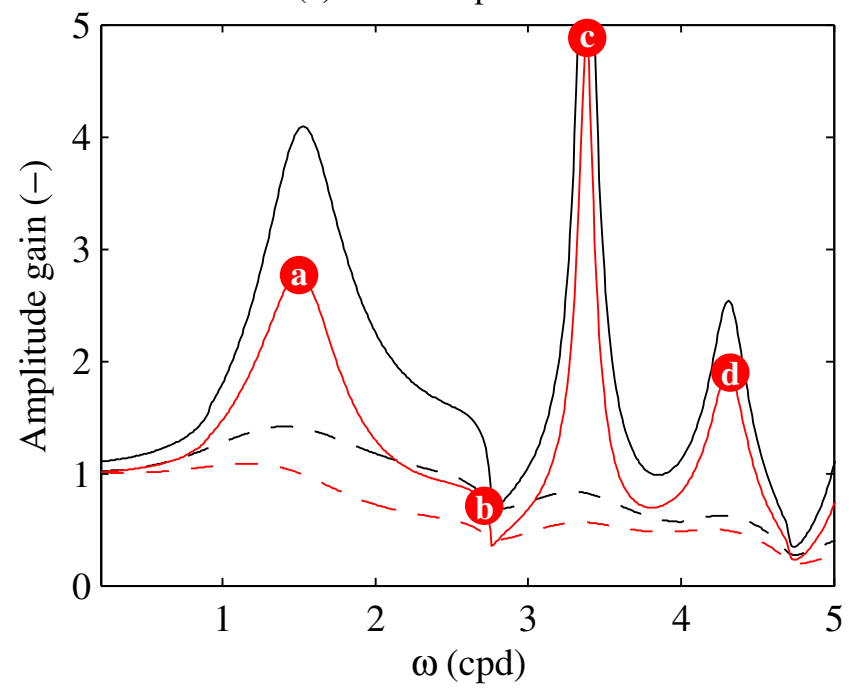

Fig. 4 Amplitude gain versus forcing frequency $\omega$ for the model geometries in Fig. 3a, b: a two compartments, b three compartments (including strait). Solid lines without bottom friction, dashed lines with bottom friction. In (a), the black and red lines indicate $A_{\text {head }}$ and $A_{\text {bight }}$, respectively. In (b), the red and blue
To quantify the 'response', we introduce the amplitude gain $A_{\text {head }}$. This indicator is defined as the elevation amplitude, scaled against the input amplitude $Z_{\text {inc }}$ and averaged over the head of the bight (thick solid line in Fig. 3a):

$A_{\text {head }}=\frac{1}{b_{2} Z_{\text {inc }}} \int\left|\hat{\eta}_{2}\right| \mathrm{d} y$.

Although $A_{\text {head }}$ is commonly used to quantify the amplitude gain (e.g. Huthnance 1980), it is less meaningful for the case with a strait, because part of the bay head is then an open boundary (Fig. 3b). We, therefore, introduce a second indicator $A_{\text {bight }}$, averaging the elevation amplitude over the complete bight (shaded area in Fig. 3a, b):

$A_{\text {bight }}=\frac{1}{b_{2} l_{2} Z_{\text {inc }}} \iint\left|\hat{\eta}_{2}\right| \mathrm{d} x \mathrm{~d} y$.

\subsection{Results for two compartments}

Figure 4a shows the amplitude gains $A_{\text {head }}$ and $A_{\text {bight }}$ as a function of forcing frequency for the twocompartment geometry (Fig. 3a), both without and with bottom friction. It is seen that both amplitude gains show qualitatively similar behaviour, with, as one may expect, the bight-averaged indicator $A_{\text {bight }}$ (red line) being somewhat lower than the head-averaged $A_{\text {head }}$ (black line).

(b) Three compartments (including strait)

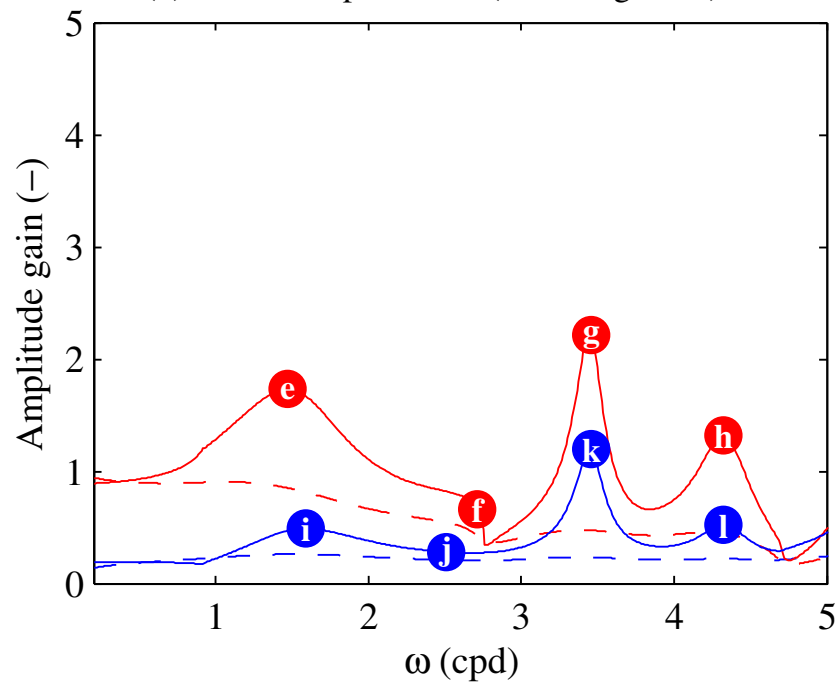

lines indicate $A_{\text {bight(N) }}$ and $A_{\text {bight(S) }}$, respectively, i.e. separately forcing the system from the north and south only. The co-tidal charts of the cases denoted by the lowercase letters $a-l$ are depicted in Fig. 5 
The curves without bottom friction (solid lines) display a peak between the diurnal band $(\omega \approx 1 \mathrm{cpd})$ and semi-diurnal band $(\omega \approx 2 \mathrm{cpd})$, a weaker response at $\omega=2.5-3 \mathrm{cpd}$ and two further peaks at higher values of the forcing frequency. As can be seen from the cotidal chart in Fig. 5a, the first peak is associated with a quarter wavelength resonance of the Kelvin mode in the Southern Bight. Next, Fig. 5b shows an example of weaker amplification in the bight, which is accompanied by higher amplitudes in the corners of the deep and wide compartment (e.g. the German Bight, region near point $E$ in Fig. 1). The second peak in the frequency-response curve represents resonance of the first Poincaré mode (Fig. 5c), whereas the third peak is a three quarter wavelength resonance of the Kelvin mode. We note that adjusting the dimensions of the model geometry may affect the order in which the Kelvin and Poincaré resonances appear as a function of $\omega$.

As shown by the dashed lines in Fig. 4a, including bottom friction causes the peaks to nearly disappear. The amplitude gain becomes nearly monotonically decreasing function of $\omega$. It should be noted that, in the simulation with bottom friction, we assume $Z=1 \mathrm{~m}$, ignore the enhancement of friction due to the simultaneous presence of other constituents $(F=1)$ and maintain $\alpha=0.6$; see Eqs. 4-5.
Fig. 5 Co-tidal charts of the twelve cases a-l highlighted in the frequency-response curves in Fig. 4 (without bottom friction). The top row pertains to the two-compartment geometry (Fig. 3a); the middle and bottom rows to the three-compartment geometry (Fig. 3b) if forced from the north or south only, respectively. Please note the different colourbars used in each row (a)

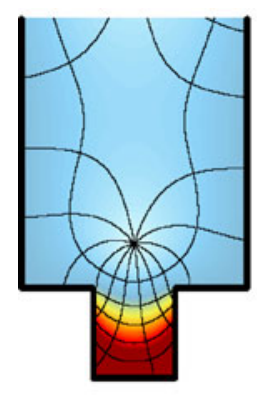

(e)

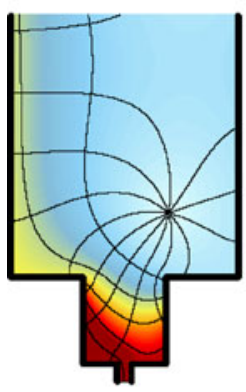

(i)

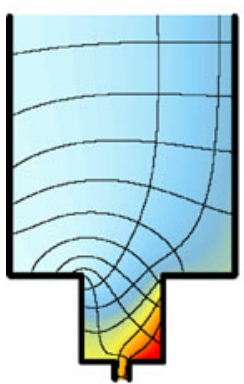

(b)

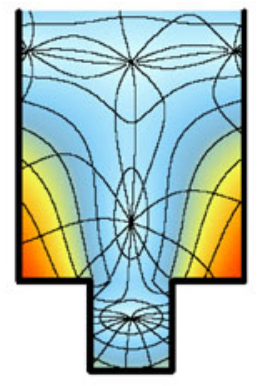

(f)

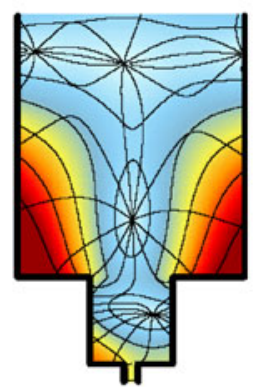

(j)

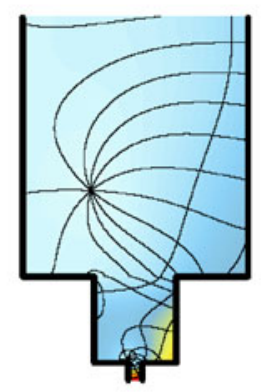

(c)

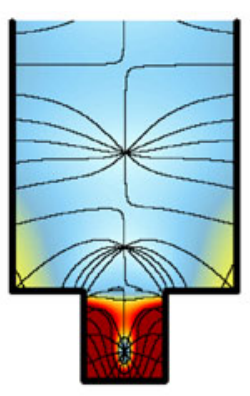

(g)

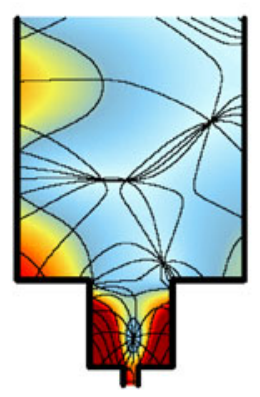

(k)

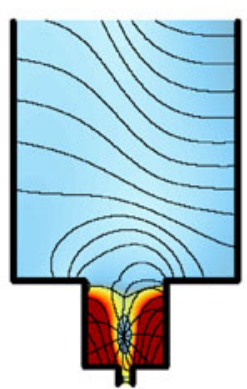

(d)

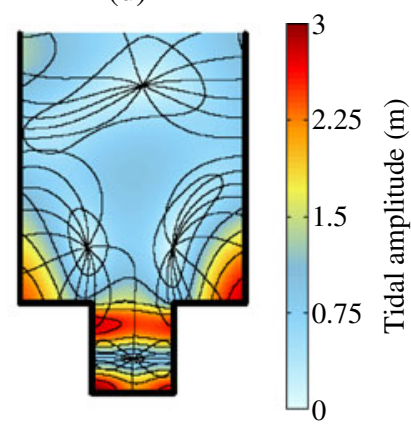

(h)

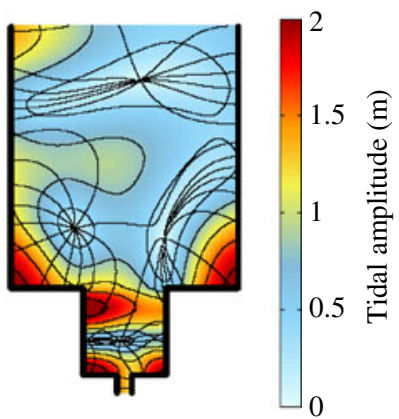

(1)

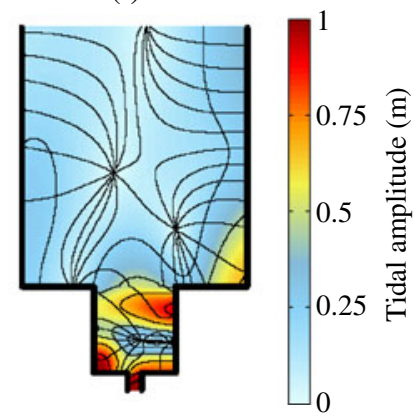




\subsection{Results for three compartments (including strait)}

Now let us proceed with the three-compartment geometry of Fig. 3b. Justified by the linearity of the problem, we may write the solution as

$\phi=\phi_{(\mathrm{N})}+\phi_{(\mathrm{S})}$,

where $\phi_{(\mathrm{N})}$ is the solution if forced from the north only and $\phi_{(\mathrm{S})}$ the solution if forced from the south only (while maintaining the other boundary as an open boundary). Accordingly, we define $A_{\text {bight(N) }}$ and $A_{\text {bight(S) }}$ as the amplitude gains of these separate solutions. It should be noted that, due to phase differences, the amplitude gain of the complete solution does not equal the sum of the individual amplitude gains, i.e. in general $A_{\text {bight }} \neq A_{\text {bight(N) }}+A_{\text {bight(S) }}$.

Figure $4 \mathrm{~b}$ shows the frequency-response curves if the three-compartment-system is forced from the north

(a) M2-tidal elevation
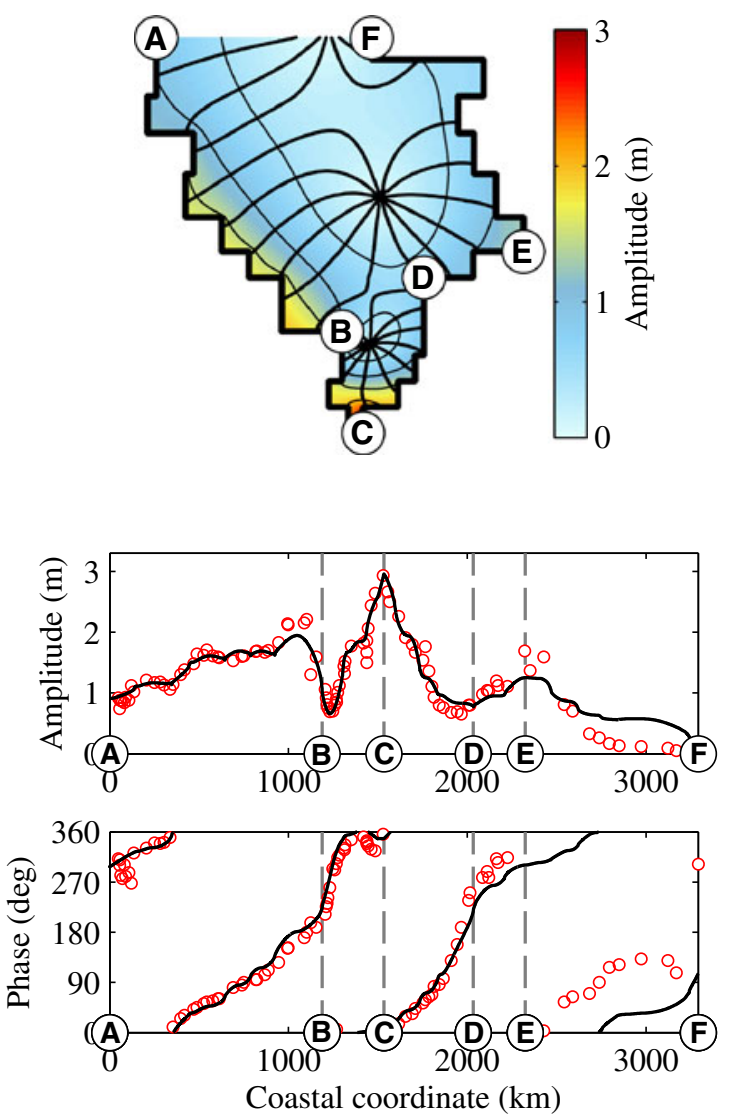

Fig. 6 Modelled amphidromic chart (top) and comparison of model results (solid lines) and observations (open circles) as a function of the coastal coordinate along $A-F$, i.e. elevation only $\left(A_{\text {bight(N) }}\right.$, red $)$ and south only ( $A_{\text {bight(S) }}$, blue $)$. For the case without bottom friction (solid lines), the curves are qualitatively similar to the case with two compartments (Fig. 4a), i.e. showing similar peaks at similar $\omega$ values, regardless whether the system is forced from the north or south. Restricting our attention first to the case with forcing from the north only, it is seen that the amplitude gain is roughly a factor 2 smaller than in the two-compartment-case, which is due to radiation of energy from the bight into the strait. The lowest values are obtained if the system is forced from the south only, which is due to (1) radiation of energy from the bight into the northern compartment and (2) the absence of a shoaling effect, because the depth in bight and strait is identical $\left(h_{2}=h_{3}=20 \mathrm{~m}\right.$; see Table 3$)$. The co-tidal charts in Fig. 5e-1 show that the resonance mechanisms identified in Section 3.2 continue to exist after the introduction of a strait and the distinction

(b) S2-tidal elevation
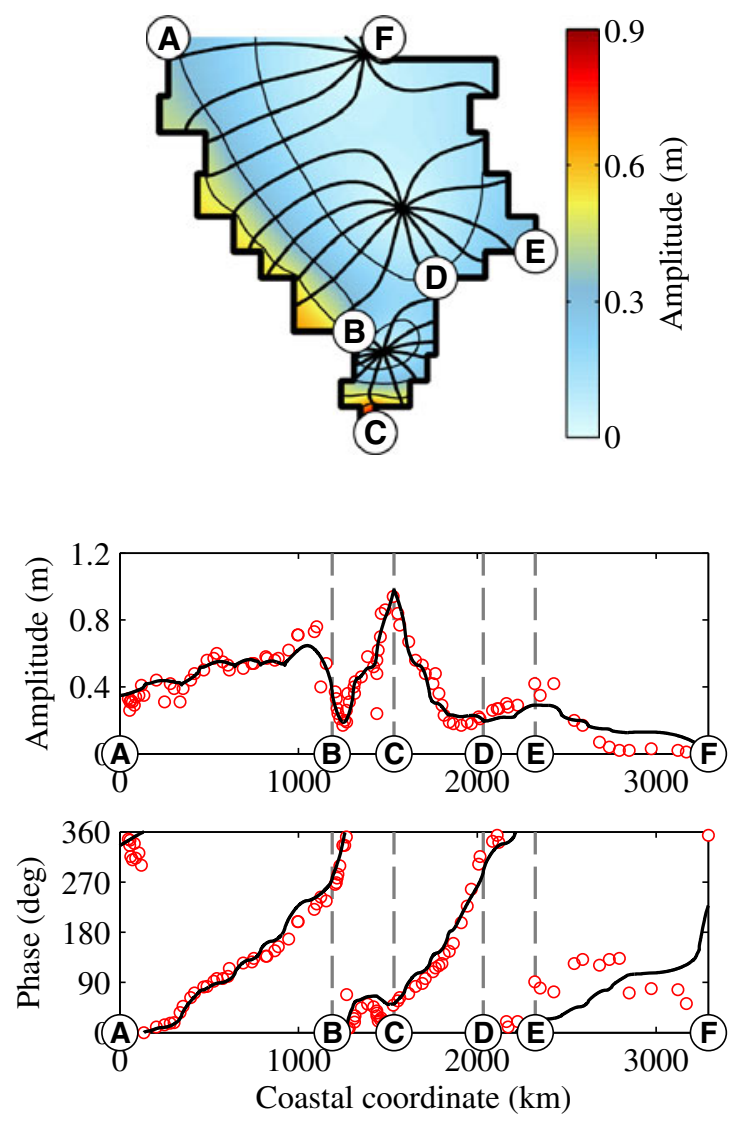

amplitudes (middle) and phases (bottom) for four constituents: a M2, b S2 and, on the next page, c K1, d O1. Note the differences in scales of the colourbars and the amplitude axes 
in forcing from either the north or south. It is seen that they occur at nearly the same frequencies, yet in a somewhat modified spatial form.

Finally, analogous to the case with two compartments, it is found that including bottom friction dampens the peaks of the frequency-response curves (dashed curves in Fig. 4b). Analogous to Section 3.2, our simulations with bottom friction use $Z=1 \mathrm{~m}, F=1$ and $\alpha=0.6$ in Eqs. 4-5.

\section{Reproducing tide observations in the North Sea}

In this section, our model will be tested against tide observations from the coastal tide stations shown in Fig. 1 (British Admiralty 2009a, b). The tide observations comprise elevation amplitudes and phases of the four dominant constituents: M2, S2 (semi-diurnal), K1 and $\mathrm{O} 1$ (diurnal). The procedure, roughly similar to that presented in Roos and Schuttelaars' (2011) study of the Adriatic Sea, Gulf of California and Persian Gulf, consists of four steps.

(c) K1-tidal elevation
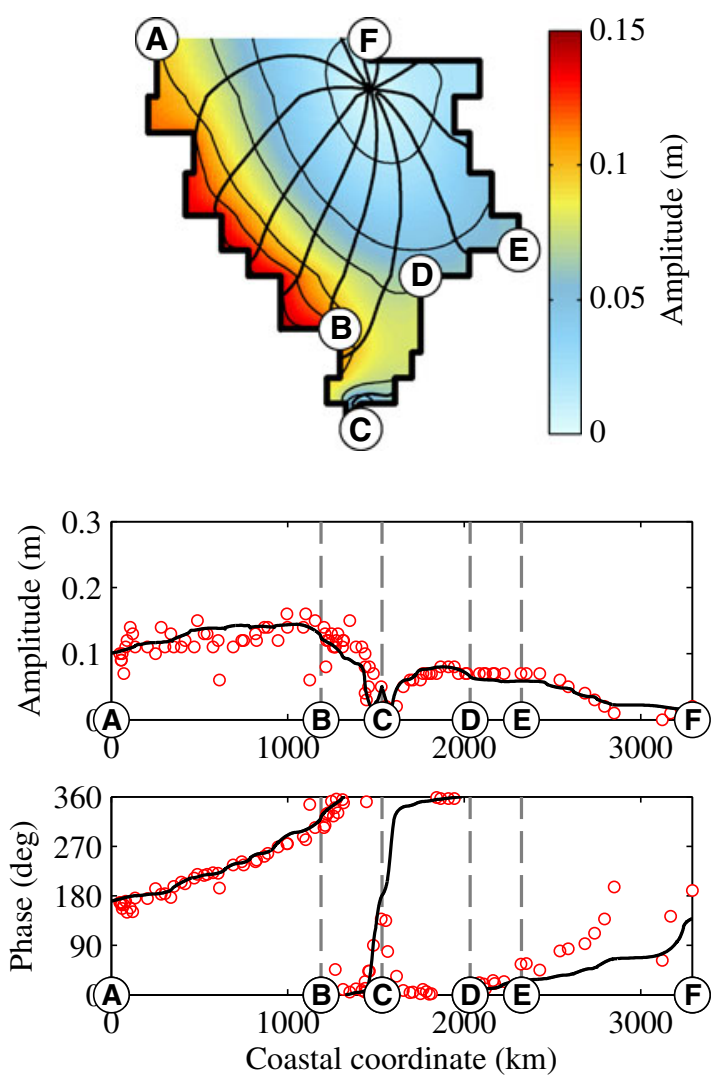

1. Choose the basin geometry by specifying the compartment dimensions $l_{j}$ and $b_{j}(j=1, \ldots, J)$, the position of the first and the centerline displacements $\delta_{j}$ of all other compartments. This step is carried out manually leading to a configuration with $J=12$ compartments and an orientation aligned with the Southern Bight (positive $x$-axis directed $13^{\circ}$ East from North). See Figs. 1, 3c and Table 3. We note that an accurate representation of the northeastern part (Norwegian Trench, Skagerrak) is not our main interest.

2. Specify $h_{j}$ as the compartment-averaged depth and $\vartheta_{j}$ as the compartment's central latitude $(j=$ $1, \ldots, J)$. Bathymetric data are taken from Amante and Eakins (2009). In calculating the compartmentaveraged depth, the parts on land are ignored.

3. Project the available coastal tide stations orthogonally onto the nearest coastal boundary. This projection allows us to visualize the observations as a function of the coastal coordinate and compare them to model results. Tide stations located upriver, up-estuary, at offshore locations or otherwise

(d) O1-tidal elevation
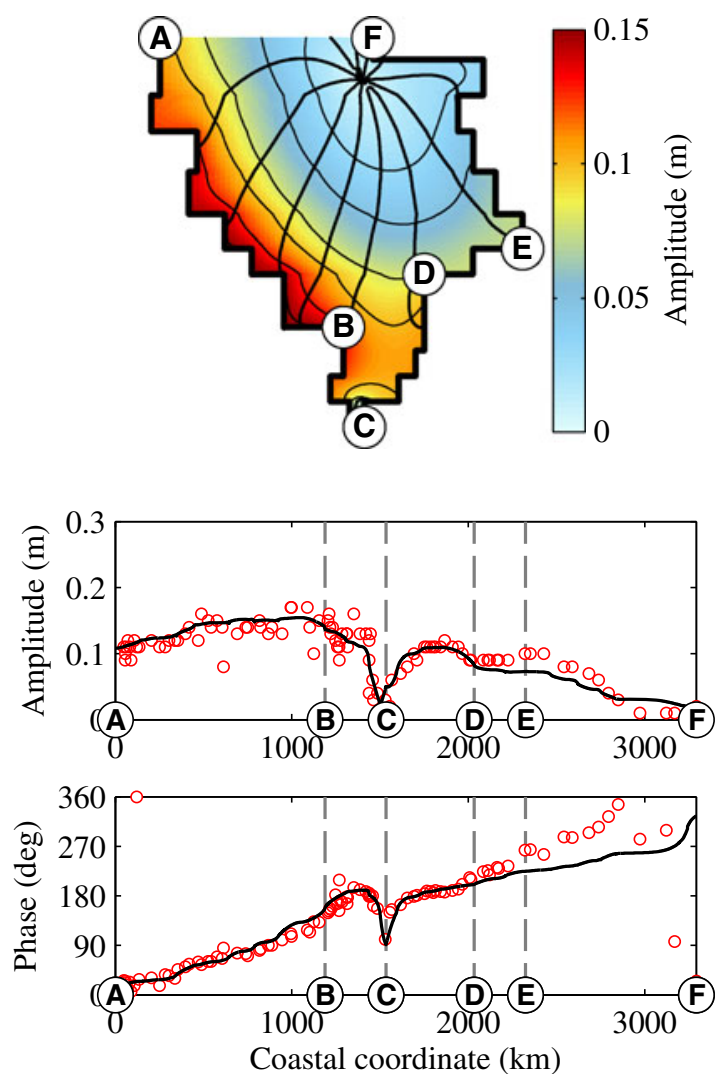

Fig. 6 (continued) 
more than $50 \mathrm{~km}$ away from the model boundaries are discarded.

4. Perform simulations using the basin set-up, depth values and latitudes as above. The amplitudes and phases $\left(Z_{(\mathrm{N})}, \varphi_{(\mathrm{N})}, Z_{(\mathrm{S})}, \varphi_{(\mathrm{S})}\right)$ of the two incoming Kelvin waves and the overall correction factor $\alpha$ serve as tuning parameters. The friction coefficients $r_{j}$ are calculated from Eqs. 4-5, using the typical elevation amplitude $Z_{\mathrm{M} 2}$ and the $F$ values from Table 2 . The simulations mentioned above are carried out for each of the four tidal constituents: M2, S2, K1 and O1 (all using the same $\alpha$-value).

The results are presented in Fig. 6. The corresponding amplitudes and phases of the incoming Kelvin waves are shown in Table 4. The best agreement between model results and coastal tide observations is obtained by setting the overall correction factor for the velocity scale in Eq. 4 at $\alpha=0.6$. The plots in Fig. 6a-d show remarkable agreement between model results and observations, regarding the coastal amplitudes and phases of all four constituents. This qualitative and quantitative agreement applies to nearly the entire North Sea (coastal coordinate $A$ to $E$ ), except the region in the north-east $(E F)$ where the bathymetry is less accurately represented than elsewhere in the model domain. However, because of the counterclockwise propagation direction of the tidal wave in the North Sea, errors in this part of the domain do not adversely affect the model results elsewhere.

The qualitative features of the M2 and $\mathrm{K} 1$ co-tidal charts from our idealized model in Fig. 6a, c show good agreement with those obtained using numerical models (e.g., Davies and Kwong 2000, see Fig. 2). The M2amphidrome in Fig. 6 a is located too far away from the German Bight and the K1-amphidrome near Norway in Fig. 6c should be virtual. Furthermore, the virtual nature of the K1-amphidrome in the Dover Strait is not reproduced by our model. Note that in conducting the simulations, we tuned to obtain agreement with coastal tide observations, rather than to obtain agreement with the positions of amphidromic points from numerical models.

Table 4 Amplitudes and phases of the incoming Kelvin waves for the simulations in Fig. 6

\begin{tabular}{lllll}
\hline Comp. & $Z_{(\mathrm{N})}(\mathrm{m})$ & $\varphi_{(\mathrm{N})}\left({ }^{\circ}\right)$ & $Z_{(\mathrm{S})}(\mathrm{m})$ & $\varphi_{(\mathrm{S})}\left({ }^{\circ}\right)$ \\
\hline M2 & 0.89 & 310 & 2.45 & 170 \\
S2 & 0.32 & 355 & 0.82 & 235 \\
K1 & 0.09 & 91 & 0.12 & 42 \\
O1 & 0.10 & 290 & 0.13 & 264 \\
\hline
\end{tabular}

\section{Further results}

\subsection{Forcing from north and south, Dover Strait, dissipation}

In this section, we will perform further simulations to unravel and better understand tidal dynamics in the North Sea. To this end, we continue to use the basin geometry of Fig. 3c, which was already used in Section 4 to reproduce the North Sea tides. For brevity, we focus on the dominant tidal constituent only: M2.

Firstly, we investigate the M2-tidal elevation amplitudes in the cases of tidal forcing from the north only $\left(Z_{(\mathrm{N})}\right.$ from Table 4 and $\left.Z_{(\mathrm{S})}=0\right)$ and, alternatively, from the south only $\left(Z_{(\mathrm{N})}=0\right.$ and $Z_{(\mathrm{S})}$ from Table 4). The corresponding coastal amplitudes, as a function of the coastal coordinate, are plotted in Fig. 7a. It is seen that the forcing through Dover Strait hardly affects the elevation amplitude along the UK coast. Furthermore, the plot alternately displays coastal stretches of constructive interference (e.g. around $C$ and along $D E$ ) and destructive interference (e.g. at point $B$ ).

Secondly, the importance of Dover Strait is studied by performing a simulation in which the Dover Strait is closed off. To this end, compartment $j=12$ is removed and the southern boundary of compartment $j=11$ is treated as a closed boundary, where according to Eq. 6, $u_{j}=0$ is imposed (and, consequently, no tidal energy enters or leaves the domain). Analogous to the simulations above, the characteristics of the incoming Kelvin wave from the north are as in Table 4. As shown in Fig. $7 b$, the resulting curve is slightly higher than the red dotted curve in Fig. 7a. Due to reflection in the Southern Bight, amplitudes are higher than in the case with an open Dover Strait and forcing from the North only, particularly in the eastern part of the domain. These results emphasize the importance of including Dover Strait as an open boundary with appropriate forcing (Brown 1987), and the strait's influence extending to the German Bight contrasts earlier beliefs (Defant 1961).

Thirdly, the importance of dissipation is assessed by performing a simulation for the M2-tide without bottom friction, i.e. for $r_{j}=0$ for all $j$. In doing so, we retain the input characteristics of the incoming Kelvin waves as given in Table 4. As shown in Fig. 7b, without bottom friction, amplitudes in the eastern part would be much higher, by a factor of more than two (blue dashed line). The increasing difference along $A B C D E F$ with the frictional case (black solid line) furthermore emphasizes the counterclockwise propagation direction of the tidal wave. 
(a) M2: role of forcing

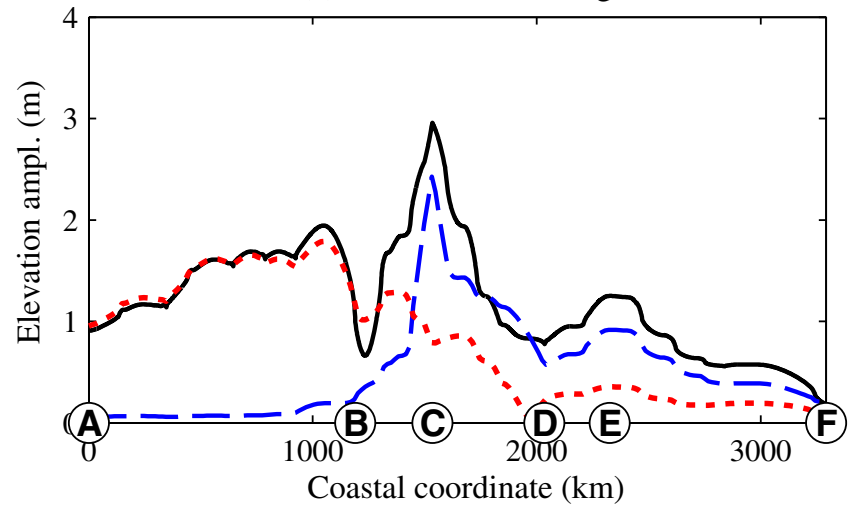

Fig. 7 M2-tidal elevation amplitudes as function of the coastal coordinate for the following cases. a Forcing from the north only (red, dotted), forcing from the south only (blue, dashed). b Simulation without bottom friction (blue, dashed); simulation

\subsection{Sea level rise}

To mimic sea level rise, we now perform simulations with an overall increase in water depth $\Delta h$ of $0-2 \mathrm{~m}$. This range surrounds the value of $1 \mathrm{~m}$, which corresponds to a high-end projection for local sea level rise along the Dutch coast onto the year 2100 (Katsman et al. 2011). The chosen $\Delta h$ value is applied uniformly to all compartments in Fig. $3 \mathrm{c}$ and Table 3. In our analysis, we assume that the horizontal boundaries of our basin are maintained, e.g. by coastal defence works. (b) M2: role of friction and Dover Strait

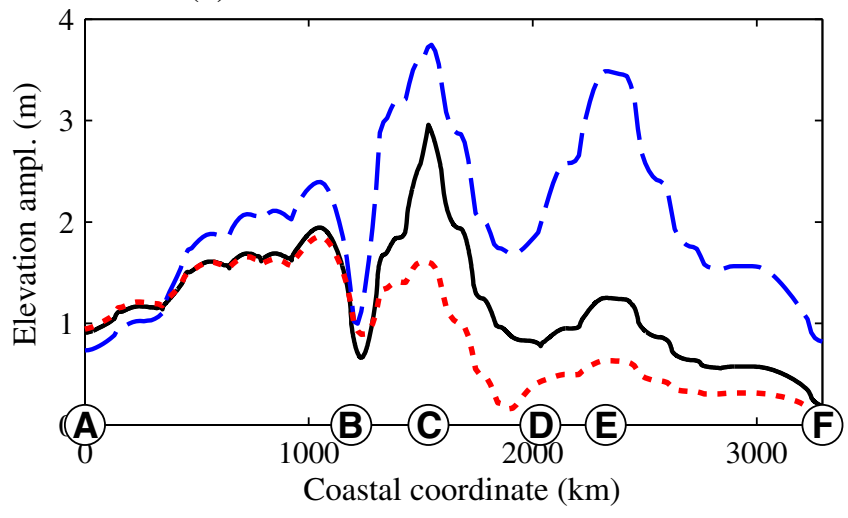

after closure of Dover Strait (red, dotted; with bottom friction). In both plots, the black solid line denotes the reference case already shown in Fig. $6 a$

According to the depth dependency of the bottom friction formulation in Eqs. 4-5, the friction coefficients experience a slight decrease. Furthermore, the tidal wave speed will increase slightly as the result of the increased water depth. As before, the amplitudes and phases of the incoming Kelvin waves are assumed to be unaffected. To assess whether this assumption is justified, one would require a larger model domain which is beyond the scope of the present study.

Fig. 8a shows the difference in coastal elevation amplitudes induced by $\Delta h=1 \mathrm{~m}$. The overall qualita- (a) M2: 1m mean sea level rise

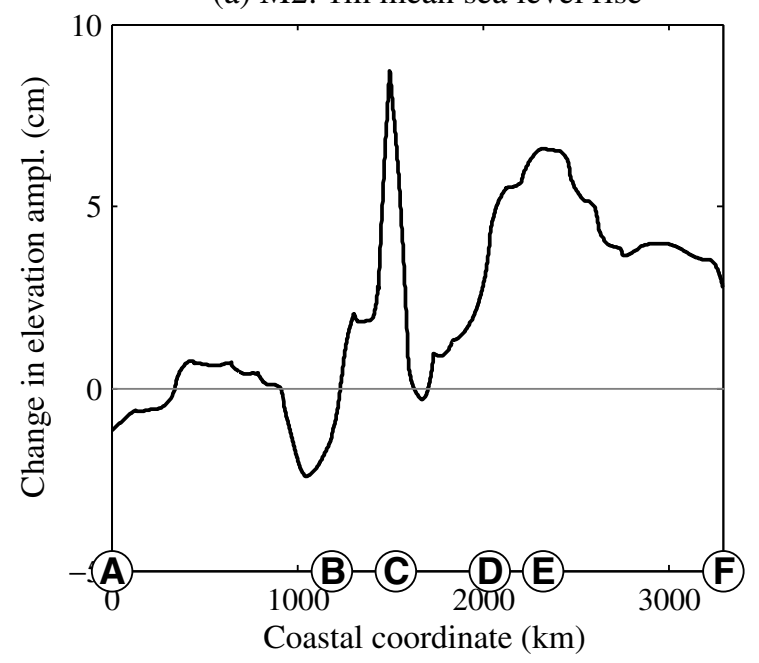

Fig. 8 Changes in coastal M2-elevation amplitudes, due to sea level rise, as a function of the coastal coordinate. a Line plot for an overall sea level rise of $\Delta h=1 \mathrm{~m}, \mathbf{b}$ colour plot for an overall (b) M2: 0 to $2 \mathrm{~m}$ mean sea level rise

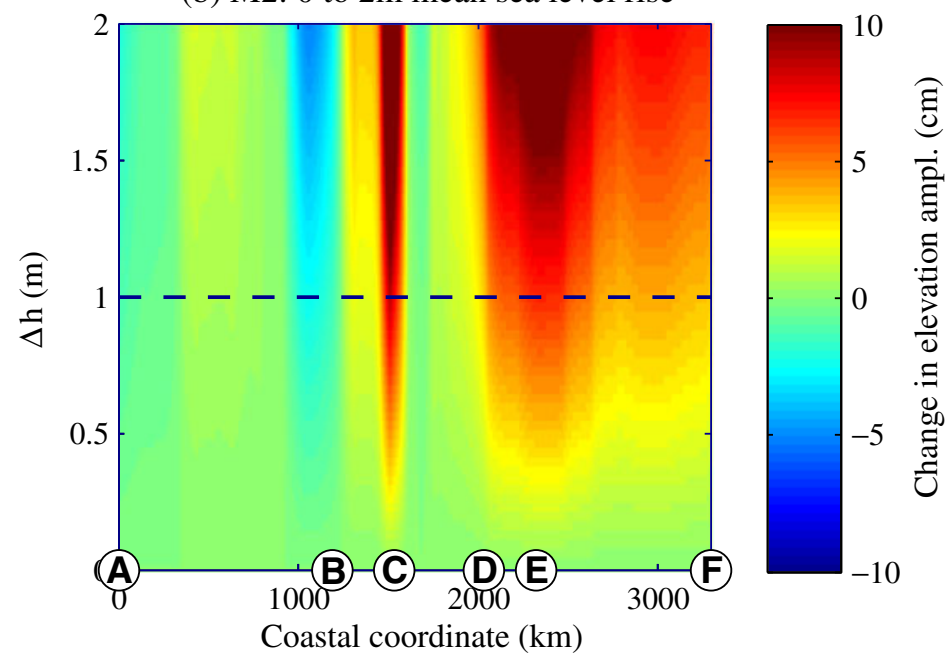

sea level rise in the range $0-2 \mathrm{~m}$. The dashed black line in the colour plot denotes the reference value used in the line plot 
(a) M2: $-1 \mathrm{~m}$ and $1 \mathrm{~m}$ depth change Southern Bight

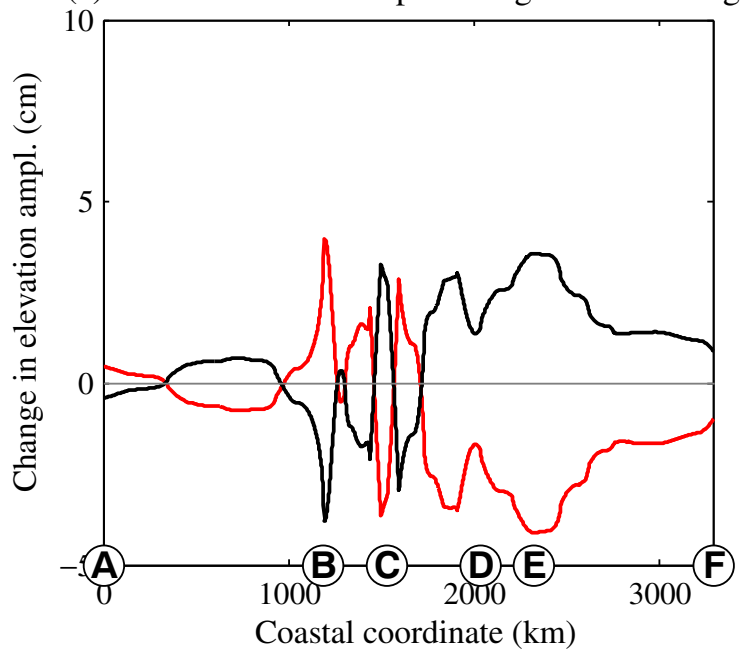

Fig. 9 Changes in coastal M2-elevation amplitudes, due to a uniform bed level change in the Southern Bight, as a function of the coastal coordinate. a Line plots for a uniform depth increase of $\Delta h_{\mathrm{SB}}=1 \mathrm{~m}$ (black) and a uniform depth decrease of (b) M2: $-2 \mathrm{~m}$ to $2 \mathrm{~m}$ depth change Southern Bight

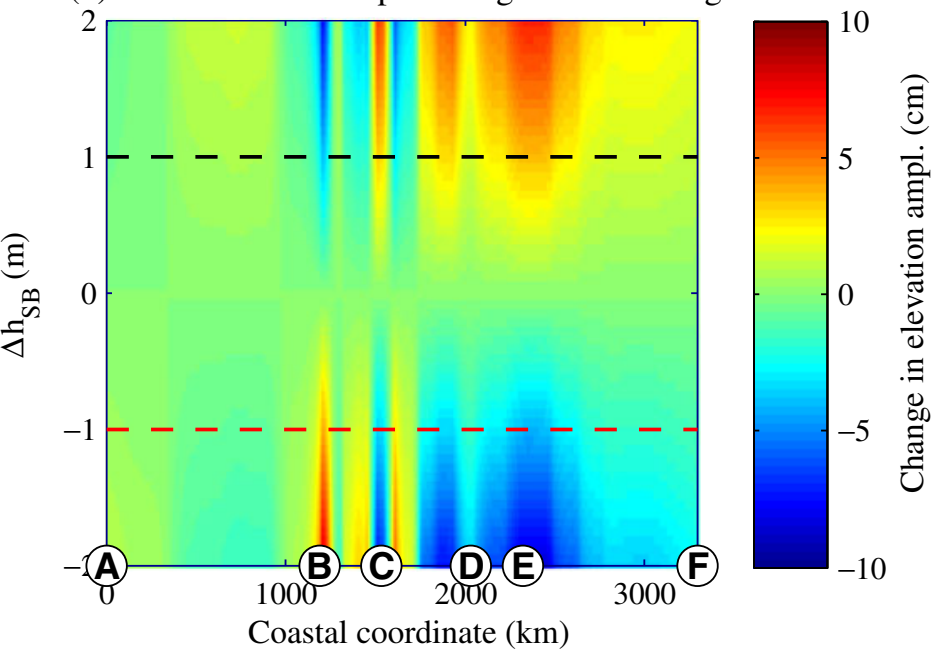

$\Delta h_{\mathrm{SB}}=1 \mathrm{~m}($ red $)$, b colour plot for a uniform depth change in the range -2 to $+2 \mathrm{~m}$. The dashed lines in the colour plot denote the reference values used in the line plots

changes than the sea level rise simulation in Fig. 8 . Roughly the inverse of this curve is obtained when making the Southern Bight $1 \mathrm{~m}$ shallower instead of deeper, suggesting a linear dependency on $\Delta h_{\mathrm{SB}}$. The colour plot in Fig. 9b shows the variation around the reference values of $\pm 1 \mathrm{~m}$. Again, the qualitative picture is insensitive to $\Delta h_{\mathrm{SB}}$ and the quantitative response is roughly linear in $\Delta h_{\mathrm{SB}}$.

\section{Discussion}

\subsection{Model properties}

The solution procedure is quick, a typical North Sea simulation taking less than a second on a personal computer. This allows us to conduct many simulations (as required e.g. in Figs. 4, 5, 8b and 9b). In our simulations to reproduce the tides in the North Sea, we have considered all aspects of basin geometry (dimensions, positioning, depth, latitude) and the friction coefficients as fixed, except for the parameter $\alpha$. We then used the amplitudes $Z_{(\mathrm{N})}$ and $Z_{(\mathrm{S})}$ and phases $\varphi_{(\mathrm{N})}$ and $\varphi_{(\mathrm{S})}$ of the incoming Kelvin waves along with the correction factor $\alpha$ as tuning parameters. We remark that the dynamics of the system is effectively controlled by three dimensionless quantities: the correction factor $\alpha$ (assumed the same for all constituents to minimize the degrees of freedom), the amplitude ratio $Z_{(\mathrm{S})} / Z_{(\mathrm{N})}$ and the phase lag $\varphi_{(\mathrm{S})}-\varphi_{(\mathrm{N})}$. This is true for ampliseen that deepening of the Southern Bight produces a curve qualitatively resembling but showing smaller 
tudes for which the $Z$ and $F$ values in Table 2 remain representative; such that the friction coefficients $r_{j}$ in Eq. 4 remain unaffected. The remaining 2 degrees of freedom then merely provide an overall multiplication factor and an overall phase shift, used to improve the agreement with observations.

There is a degree of arbitrariness in choosing the basin geometry, particularly its orientation, the number of compartments as well as their dimensions and relative position. Because of our interest in the Southern Bight, we have chosen the orientation of the Southern Bight. Other simulations, not reported here, show that aligning the geometry with the deeper northern part leads to similar results (although fitting the direction of Dover Strait is somewhat awkward). Alternatively, simulations with fewer compartments, also not reported here, lack the more precise quantitative agreement with observations. The inaccuracies in the basin geometry induce (quantitative) inaccuracies in both the physics and the projection procedure.

On the other hand, increasing the number of compartments does not further improve the agreement, merely increasing the computational time. The absence of lateral depth variations then becomes a crucial limitation. Allowing for a lateral topographic step in each compartment, effectively creating two subcompartments of uniform depths $h_{j}$ and $h_{j}^{\prime}$, would improve our representation of bathymetry and, hence, the agreement between model results and observations (especially if additional compartments would be added to represent the Skagerrak). The fundamental wave solutions can then no longer be found fully analytically; a relatively straight-forward search routine for the wave numbers is required (Roos and Schuttelaars 2011). Alternatively, one may also adopt an arbitrary, smooth transverse depth profile in each compartment. However, the transverse structure of the fundamental wave solutions must then be found numerically, which is computationally relatively expensive (de Boer et al. 2011).

\subsection{Resonance properties}

Now let us interpret the resonance properties against the background of previous studies. The twocompartment geometry studied in Section 3.2 (Fig. 3a), consisting of a relatively shallow and narrow bight $(j=2)$ connected to a deeper and wider compartment $(j=1)$, can be interpreted as an intermediate geometry between two extremes studied previously in different contexts: a shallow rectangular gulf opening to a deeper semi-infinite ocean (Garrett 1975; Huthnance 1980) and the channel model without width variations and with a longitudinal depth step (Webb 1976;
Roos and Schuttelaars 2011). These geometries are approximated by our model in the limits of $b_{1} / b_{2} \rightarrow \infty$ and $b_{1} / b_{2} \downarrow 1$, respectively.

A further complication is encountered by our inclusion of a third compartment representing a strait as a second connection with the ocean (see Section 3.3 and Fig. 3b). Due to the linearity of the problem, the solution can be conveniently written as the superposition of two solutions: one forced at the open boundary of the deep and wide compartment only, the other forced through the strait only. However, since these solutions may locally interfere in a constructive, destructive or neutral manner, the final amplification strongly depends on the relative amplitude and phase of the two types of boundary forcing. The presence of two open boundaries thus complicates the interpretation of resonance mechanisms.

By varying the forcing frequency in the two- and three-compartment model, we identified the following resonance mechanisms:

- Kelvin resonance, i.e. the generalization of the classical quarter wavelength resonance to the case including rotation, radiation damping and bay width (Garrett 1975; Webb 1976; Huthnance 1980; Roos and Schuttelaars 2011).

- Poincaré resonance, i.e. the amplification of crossbay modes in the shallow and narrow compartment (Huthnance 1980; Roos and Schuttelaars 2011). This mode was not found by Garrett (1975) due to the narrow-gulf assumption. The cases with an amplified response in the corners of the wide compartment (e.g. the German Bight) show that this type of amplification may also occur in the deep and wide compartment. In our example, this phenomenon is accompanied by a rather weak response in the bight.

After including a strait and separately forcing the system from the north and south, these resonances continue to occur. The response is weaker, particularly in the case of forcing through the strait, and the spatial structure modified. Clearly, the frequency-response curves shown in Fig. 4 are much more complex than those of a rectangular bay or a Helmholtz model.

\section{Conclusions}

We have developed an idealized process-based model to gain insight in the tidal dynamics of the North Sea. By accounting for bottom friction, changes in depth and width and the presence of two open boundaries, our model extends and combines earlier work (Taylor 1922; 
Godin 1965; Rienecker and Teubner 1980; Roos and Schuttelaars 2011). The solution method combines a superposition of wave solutions per compartment with a collocation method, thus accounting for no-normal flow at the longitudinal closed boundaries and the matching conditions between adjacent compartments. The resulting model is quick to run and allows inclusion of sufficient level of geometrical detail for a comparison with observations.

First, we studied the general resonance properties of a highly simplified geometry with two compartments, representing the deep and wide Northern North Sea and the shallow and narrow Southern North Sea. By varying the tidal frequency while neglecting bottom friction, we identified both Kelvin and Poincaré resonance. These resonances continue to exist when adding a third compartment that accounts for the Dover Strait and subsequently forcing the system from the North and South only. However, resonance peaks are lower than in the two-compartment case. The response when being simultaneously forced from the North and South, as in the tidal case, strongly depends on the relative amplitude and phase. Incorporating bottom friction further reduces the resonance peaks. Due to the differences in geometry, our findings add to results from earlier studies on basins connected to deeper and in some cases also wider bodies of water (Garrett 1975; Webb 1976; Huthnance 1980; Roos and Schuttelaars 2011).

Next, we adopted a more detailed geometry with 12 compartments fitted to the coastline of the North Sea. Comparison with tide observations along the North Sea coast, i.e. tidal range and phase of the principal semi-diurnal (M2 and S2) and diurnal constituents (K1 and O1), shows good agreement. These results give confidence in applying our idealized model to situations for which no data are available. This leads to the following results:

- The solutions due to the tidal energy coming in from north and south create alternating patterns of constructive and destructive interference along the coast. Closure of Dover Strait would imply significant decreases in M2-tidal range along the German coast.

- Without bottom friction, coastal amplitudes would be larger, particularly in the eastern part of the North Sea (roughly a factor 2 for M2).

- To mimic sea level rise, a simulation with a $1 \mathrm{~m}$ increase in water depth, while leaving the horizontal boundaries of the system and the amplitudes/ phases of the incoming Kelvin waves unaffected, leads to an increase in coastal M2-elevation ampli- tudes up to $8 \mathrm{~cm}$, particularly in the eastern part of the North Sea.

- Bed level variations of $\pm 1 \mathrm{~m}$ uniformly applied to the Southern Bight lead to changes in coastal M2elevation amplitudes of the order of $\mathrm{cm}$, particularly in the Southern Bight itself and in the German Bight.

Acknowledgements This work is supported by the Netherlands Technology Foundation STW, the applied science division of NWO and the Netherlands Ministry of Economic Affairs. The authors thank Henk Schuttelaars for his comments.

Open Access This article is distributed under the terms of the Creative Commons Attribution Noncommercial License which permits any noncommercial use, distribution, and reproduction in any medium, provided the original author(s) and source are credited.

\section{Appendix}

\section{A Calculation of friction coefficients}

To calculate the friction coefficient $F$ in Eq. 4 for each of the tidal constituents in Table 2, we follow the procedure proposed by Inoue and Garrett (2007). We consider a (unidirectional) tidal signal with a dominant M2-component and three smaller components (S2, $\mathrm{K} 1$ and $\mathrm{O} 1)$ of relative amplitude $\epsilon_{\mathrm{S} 2}, \epsilon_{\mathrm{K} 1}$ and $\epsilon_{\mathrm{O} 1}$, respectively.

The fourth order approximations of the friction coefficients of the dominant M2-component and the weaker $\mathrm{S} 2$-component are given by

$$
\begin{aligned}
F_{\mathrm{M} 2}=1+ & \frac{3}{4}\left(\epsilon_{\mathrm{S} 2}^{2}+\epsilon_{\mathrm{K} 1}^{2}+\epsilon_{\mathrm{O} 1}^{2}\right)-\frac{3}{64}\left(\epsilon_{\mathrm{S} 2}^{4}+\epsilon_{\mathrm{K} 1}^{4}+\epsilon_{\mathrm{O} 1}^{4}\right) \\
& -\frac{3}{16}\left(\epsilon_{\mathrm{S} 2}^{2} \epsilon_{\mathrm{K} 1}^{2}+\epsilon_{\mathrm{S} 2}^{2} \epsilon_{\mathrm{O} 1}^{2}+\epsilon_{\mathrm{K} 1}^{2} \epsilon_{\mathrm{O} 1}^{2}\right) \\
F_{\mathrm{S} 2}=\frac{3}{2}[1+ & \frac{1}{4}\left(\frac{\epsilon_{\mathrm{S} 2}^{2}}{2}+\epsilon_{\mathrm{K} 1}^{2}+\epsilon_{\mathrm{O} 1}^{2}\right) \\
+ & \frac{1}{64}\left(\frac{\epsilon_{\mathrm{S} 2}^{4}}{3}+\epsilon_{\mathrm{K} 1}^{4}+\epsilon_{\mathrm{O} 1}^{4}\right) \\
+ & \left.\frac{1}{16}\left(\frac{\epsilon_{\mathrm{S} 2}^{2} \epsilon_{\mathrm{K} 1}^{2}}{2}+\frac{\epsilon_{\mathrm{S} 2}^{2} \epsilon_{\mathrm{O} 1}^{2}}{2}+\epsilon_{\mathrm{K} 1}^{2} \epsilon_{\mathrm{O} 1}^{2}\right)\right]
\end{aligned}
$$

respectively. (Eq. 13 is given by Inoue and Garrett (2007); Eq. 14 provides the fourth order terms not specified in their study.)

Note that the dependencies of $F_{\mathrm{S} 2}$ on the terms involving $\epsilon_{\mathrm{S} 2}$ differ from the dependencies on terms not involving $\epsilon_{\mathrm{S} 2}$. Expressions for $F_{\mathrm{K} 1}$ and $F_{\mathrm{O} 1}$ follow directly from Eq. 14 by interchanging the roles of $\epsilon_{\mathrm{S} 2}$, 
$\epsilon_{\mathrm{K} 1}$ and $\epsilon_{\mathrm{O} 1}$. Table 2 in the main text shows the $\epsilon$ - and $F$ values.

\section{B Wave solutions in a channel of uniform depth}

This appendix contains analytical expressions of the wave solutions in an infinitely long channel of uniform width $b_{j}$ (lateral boundaries at $y=0$ and $y=b_{j}$ ) and uniform depth $h_{j}$ (with $j=1,2$ ), including bottom friction:

$$
\left(\begin{array}{c}
\eta_{j, m}^{\oplus} \\
u_{j, m}^{\oplus} \\
v_{j, m}^{\oplus}
\end{array}\right)=Z^{\prime}\left(\begin{array}{l}
\tilde{\eta}_{j, m}^{\oplus}(y) \\
\tilde{u}_{j, m}^{\oplus}(y) \\
\tilde{v}_{j, m}^{\oplus}(y)
\end{array}\right) \exp \left(i\left[\omega t-k_{j, m}^{\oplus} x\right]\right),
$$

with amplitude factor $Z^{\prime}$ (in $\mathrm{m}$ ), wave number $k_{j, m}^{\oplus}$ and lateral structures $\tilde{\eta}_{j, m}^{\oplus}(y), \tilde{u}_{j, m}^{\oplus}(y)$ and $\tilde{v}_{j, m}^{\oplus}(y)$. For the Kelvin mode $(m=0)$ propagating in the positive $x$ direction, we obtain

$k_{j, 0}^{\oplus}=\gamma_{j} K_{j}$,

$$
\left(\begin{array}{l}
\tilde{\eta}_{j, m}^{\oplus}(y) \\
\tilde{u}_{j, m}^{\oplus}(y) \\
\tilde{v}_{j, m}^{\oplus}(y)
\end{array}\right)=\left(\begin{array}{c}
1 \\
\gamma_{j}^{-1} \sqrt{g / h_{j}} \\
0
\end{array}\right) \exp \left(\frac{-y}{\gamma_{j} R_{j}}\right)
$$

respectively. Here, we have used the reference wave number $K_{j}$, the Rossby deformation radius $R_{j}$ (both typical for a classical Kelvin wave without friction) and a frictional correction factor, given by

$$
K_{j}=\frac{\omega}{\sqrt{g h_{j}}}, \quad R_{j}=\frac{\sqrt{g h_{j}}}{f}, \quad \gamma_{j}=\sqrt{1-\frac{i r_{j}}{\omega h_{j}}},
$$

respectively.

The wave number and lateral structures of the $m$ th Poincaré mode $(m>0)$ propagating (if free) or decaying (if evanescent) in the positive $x$-direction are given by

$$
\begin{aligned}
& k_{j, m}^{\oplus}=\sqrt{\gamma_{j}^{2} K_{j}^{2}-\gamma_{j}^{-2} R_{j}^{-2}-\beta_{m}^{2}}, \\
& \tilde{\eta}_{j, m}^{\oplus}(y)=\cos \left(\beta_{m} y\right)-\frac{f k_{j, m}^{\oplus}}{\beta_{m} \gamma_{j}^{2} \omega} \sin \left(\beta_{m} y\right), \\
& \tilde{u}_{j, m}^{\oplus}(y)=\frac{g k_{j, m}^{\oplus}}{\gamma_{j}^{2} \omega} \cos \left(\beta_{m} y\right)-\frac{f}{\beta_{m} \gamma_{j}^{2} h_{j}} \sin \left(\beta_{m} y\right), \\
& \tilde{v}_{j, m}^{\oplus}(y)=\frac{-i \omega}{\beta_{m} \gamma_{j}^{2} h_{j}}\left[\gamma_{j}^{2}-\frac{k_{j, m}^{\oplus 2}}{K_{j}^{2}}\right] \sin \left(\beta_{m} y\right),
\end{aligned}
$$

respectively, with $\beta_{m}=m \pi / b_{j}$.
The modes propagating or decaying in the negative $x$-direction are defined analogous to Eq. 15, but now using a superscript $\ominus$ instead of a superscript ${ }^{\oplus}$. By symmetry, the two type of modes $\tilde{\phi}_{j, m}^{\oplus}$ and $\tilde{\phi}_{j, m}^{\ominus}$ satisfy the following relationships:

$$
\tilde{\phi}_{j, m}^{\ominus}(y)=\left(\begin{array}{c}
\tilde{\eta}_{j, m}^{\oplus}\left(b_{j}-y\right) \\
-\tilde{u}_{j, m}^{\oplus}\left(b_{j}-y\right) \\
-\tilde{v}_{j, m}^{\oplus}\left(b_{j}-y\right)
\end{array}\right), \quad k_{j, m}^{\ominus}=-k_{j, m}^{\oplus} .
$$

Finally, dealing with the lateral displacements of the compartments relative to one another requires suitable translations of the $y$-coordinate in the above solutions.

\section{References}

Amante C, Eakins BW (2009) ETOPO1 1 arc-minute global relief model: Procedures, data sources and analysis. NOAA Technical Memorandum NESDIS NGDC-24, National Geophysical Data Center

Arbic BK, St-Laurent P, Sutherland G, Garrett C (2007) On the resonance and influence of the tides in Ungava Bay and Hudson Strait. Geophys Res Lett 34:L17,606. doi:10.1029/ 2007GL030845

Barthel K, Gadea HG, Sandal CK (2004) A mechanical energy budget for the North Sea. Cont Shelf Res 24(2):167-187. doi:10.1016/j.csr.2003.10.006

de Boer WP, Roos PC, Hulscher SJMH, Stolk A (2011) Impact of mega-scale sand extraction on tidal dynamics in semienclosed basins: an idealized model study with application to the North Sea. Coast Eng 58(8):678-689. doi:10.1016/j. coastaleng.2011.03.005

British Admiralty (2009a) NP201-2010 Admiralty Tide Tables 2010, vol 1. United Kingdom Hydrographic Office, Taunton

British Admiralty (2009b) NP202-2010 Admiralty Tide Tables 2010, vol 2. United Kingdom Hydrographic Office, Taunton

Brown T (1987) Kelvin wave reflection at an oscillating boundary with applications to the North Sea. Cont Shelf Res 7:351365. doi:10.1016/0278-4343(87)90105-1

Brown T (1989) On the general problem of Kelvin wave reflection at an oscillating boundary. Cont Shelf Res 9:931937. doi:10.1016/0278-4343(89)90066-6

Carbajal N, Piney S, Rivera JG (2005) A numerical study on the influence of geometry on the formation of sandbanks. Ocean Dyn 55:559-568. doi:10.1007/s10236-005-0034-1

Davies AM, Jones JE (1995) The influence of bottom and internal friction upon tidal currents: Taylor's problem in three dimensions. Cont Shelf Res 15(10):1251-1285. doi:10.1016/ 0278-4343(94)00076-Y

Davies AM, Jones JE (1996) The influence of wind and wind wave turbulence upon tidal currents: Taylor's problem in three dimensions with wind forcing. Cont Shelf Res 16(1):25-99. doi:10.1016/0278-4343(95)00004-K

Davies AM, Kwong SCM (2000) Tidal energy fluxes and dissipation on the European continental shelf. J Geophys Res 105(C9):21,969-21,989

Defant A (1961) Physical oceanography. Pergamon, New York

Dyer KR, Huntley DA (1999) The origin, classification and modelling of sand banks and ridges. Cont Shelf Res 19(10):12851330. doi:10.1016/S0278-4343(99)00028-X 
Fang Z, Ye A, Fang G (1991) Solutions of tidal motions in a semi-enclosed rectangular gulf with open boundary condition specified. In: Parker BB (ed) Tidal hydrodynamics, Wiley, pp 153-168

Garrett C (1972) Tidal resonance in the Bay of Fundy and Gulf of Maine. Nature 238:441-443

Garrett C (1975) Tides in gulfs. Deep-Sea Res 22(1):23-35. doi:10.1016/0011-7471(75)90015-7

Gerritsen H, de Vries JW, Philippart ME (1995) The Dutch continental shelf model. In: Lynch DR, Davies AM (eds) Quantitative Skill Assessment for Coastal Ocean Models, AGU, Coastal Estuarine Stud., vol 47, pp 425-467

Gill AE (1982) Atmosphere-Ocean Dynamics. Academic, New York

Godin G (1965) The M2 tide in the Labrador Sea, Davis Strait and Baffin Bay. Deep Sea Res 12(4):469-477. doi: 10.1016/0011-7471(65)90401-8

Godin G (1993) On tidal resonance. Cont Shelf Res 13(1):89-107. doi:10.1016/0278-4343(93)90037-X

Hendershott MC, Speranza A (1971) Co-oscillating tides in long, narrow bays; the Taylor problem revisited. Deep-Sea Res 18(10):959-980. doi:10.1016/0011-7471(71)90002-7

Huthnance JM (1980) On shelf-sea 'resonance' with application to Brazilian M3 tides. Deep-Sea Res 27(5):347-366. doi:10.1016/0198-0149(80)90031-X

Huthnance JM (1991) Physical oceanography of the North Sea. Ocean Shorel Man 16:199-231

Inoue R, Garrett C (2007) Fourier representation of quadratic friction. J Phys Oceanogr 37:593-610. doi:10.1175/JPO2999.1

Jeffreys H (1970) The Earth: its origin, history and physical constitution, 5th edn. Cambridge University Press, Cambridge

Jung KT, Park CW, Oh IS, So JK (2005) An analytical model with three sub-regions for M2 tide in the Yellow Sea and the East China Sea. Ocean Sc J 40(4):191-200. doi:10.1007/ BF03023518

Kang YQ (1984) An analytic model of tidal waves in the Yellow Sea. J Mar Res 42(3):473-485

Katsman CA, Sterl A, Beersma JJ, van den Brink HW, Church JA, Hazeleger W, Kopp RE, Kroon D, Kwadijk J, Lammersen R, Lowe J, Oppenheimer M, Plag HP, Ridley $\mathrm{J}$, von Storch H, Vaughan DG, Vellinga P, Vermeersen LLA, van de Wal RSW, Weisse R (2011) Exploring highend scenarios for local sea level rise to develop flood protection strategies for a low-lying delta-the Netherlands as an example. Clim Change. doi:10.1007/s10584-011-0037-5

Kowalik Z (1979) A note on the co-oscillating M2-tide in the Arctic Ocean. Ocean Dyn (Dt Hydrogr Z) 32(3):100-112. doi:10.1007/BF02226997
Mosetti R (1986) Determination of the current structure of the M2 tidal component in the northern Adriatic by applying the rotary analysis to the Taylor problem. Boll Oceanol Teor Appl 4:165-172

Otto L, Zimmerman JTF, Furnes GK, Mork M, Saetre R, Becker G (1990) Review of the physical oceanography of the North Sea. Neth J Sea Res 26(2-4):161-238. doi:10.1016/ doi:0077-7579(90)90091-T

Pingree RD (1983) Spring tides and quadratic friction. Deep-Sea Res 30(9):929-944, doi:10.1016/0198-0149(83)90049-3

Rienecker MM, Teubner MD (1980) A note on frictional effects in Taylor's problem. J Mar Res 38(2):183-191

Rizal S (2000) The role of non-linear terms in the shallow water equation with the application in three-dimensional tidal model of the Malacca Strait and Taylor's problem in low geographical latitude. Cont Shelf Res 20(15):1965-1991. doi:10.1016/S0278-4343(00)00059-5

Rizal S (2002) Taylor's problem-influences on the spatial distribution of real and virtual amphidromes. Cont Shelf Res 22(15):2147-2158. doi:10.1016/S0278-4343(02)00068-7

Roos PC, Schuttelaars HM (2009) Horizontally viscous effects in a tidal basin: extending Taylor's problem. J Fluid Mech 640:423-441. doi:10.1017/S0022112009991327

Roos PC, Schuttelaars HM (2011) Influence of topography on tide propagation and amplification in semi-enclosed basins. Ocean Dyn 61(1):21-38. doi:10.1007/s10236-010-0340-0

Sinha B, Pingree RD (1997) The principal lunar semidiurnal tide and its harmonics: baseline solutions for M2 and M4 constituents in the North-West European Continental Shelf. Cont Shelf Res 17(11):1321-1365. doi:10.1016/S02784343(97)00007-1

Sutherland G, Garrett C, Foreman M (2005) Tidal resonance in Juan de Fuca Strait and the Strait of Georgia. J Phys Oceanogr 35(7):1279-1286

Taylor GI (1922) Tidal oscillations in gulfs and rectangular basins. Proc Lond Math Soc 20(1):148-181. doi:10.1112/ $\mathrm{plms} / \mathrm{s} 2-20.1 .148$

Verlaan M, Zijderveld A, de Vries H, Kroos H (2005) Operational storm surge forecasting in the Netherlands: developments in the last decade. Phil Trans R Soc A 363(1831):14411453. doi:10.1098/rsta.2005.1578

Webb DJ (1976) A model of continental-shelf resonances. DeepSea Res 23(1):1-15. doi:10.1016/0011-7471(76)90804-4

Xia Z, Carbajal N, Südermann J (1995) Tidal current amphidromic system in semi-enclosed basins. Cont Shelf Res 15(2-3):219-240. doi:10.1016/0278-4343(94)E0006-8

Yanagi T (1987) Kelvin wave reflection with phase lag in the Bungo Channel. J Oceanogr 43(6):377-382. doi:10.1007/ BF02109290 